\title{
O Facebook como espaço de interação, colaboração e aprendizagem: uma reflexão sob a perspectiva discente
}

\author{
Adriana Alves Novais Souza1, Henrique Nou Schneider ${ }^{2}$ \\ ${ }^{1}$ Mestranda em Educação - Universidade Federal de Sergipe (UFS), professor da rede \\ pública estadual, membro do Grupo de Estudos e Pesquisa em Informática na Educação \\ (GEPIED) UFS/CNPq \\ ${ }^{2}$ Professor do Núcleo de Pós-graduação em Educação e de Computação - Universidade \\ Federal de Sergipe (UFS), coordenador do Grupo de Estudo e Pesquisa em Informática \\ na Educação (GEPIED) UFS/CNPq \\ dria.novais.souza@gmail.com, hnseterra.com.br
}

\begin{abstract}
The article discusses the need for practical education be tied to the world of digital technologies, expanding the times and formal learning spaces. Starting from the use of a social network - Facebook - like learning environment to complement classroom teaching practices, aimed to investigate the student on the look of the proposal, particularly in relation to the acquisition of content, collaboration with others and their participation in the process. This is a research Master's in progress, to which interests understand the (mis) direction for teachers using social networks as an informal learning environment, the first phase of analysis on the questionnaires, shows the positivity of the proposal, in the context of participant.
\end{abstract}

Resumo. $O$ artigo discute a necessidade da prática de ensino estar atrelada ao universo das tecnologias digitais, expandindo os tempos e espaços formais de aprendizagem. Partindo do uso de uma rede social - o Facebook - como ambiente de aprendizagem complementar às práticas de ensino presencial, buscou-se conhecer o olhar do aluno diante da proposta, principalmente em relação à aquisição dos conteúdos, à colaboração com os demais e sua participação no processo. Trata-se de uma pesquisa de Mestrado em andamento, à qual interessa compreender os (des) caminhos docentes para o uso das redes sociais como ambiente informal de aprendizagem, cuja primeira fase de análise, relativa aos questionários aplicados, evidencia a positividade da proposta, no contexto dos participantes.

\section{Introdução}

Há pouco menos que uma década, observa-se a vertiginosa expansão da internet e sua evolução a partir de sua segunda geração, a web 2.0, que transformou os indivíduos de meros consumidores de informação a produtores de conteúdos e conhecimentos, em interação e colaboração com seus pares. Ainda, possibilitou o surgimento de diversos softwares e ferramentas para trocas sociais interativas, como as redes sociais online, que têm possibilitado um enorme fluxo de comunicação instantânea entre pessoas das mais diversas nacionalidades, numa total convergência de tempo e espaço que fazem da internet uma importante ferramenta de desenvolvimento que pode ser explorada no universo educacional [KERCKHOVE, 2008].

Parte dessa expansão é creditada ao surgimento dos sites de redes sociais, tais como Orkut, Flikr, Twitter, MySpace, Facebook, etc., cujas características pretendem 
atender a perfis e contextos dos mais diversos usuários, atraindo um grande número de usuários, especialmente adolescentes e adultos jovens [CIRIBELLI e PAIVA, 2011]. Atualmente, o Brasil é o $4^{\circ}$ país com maior número de nativos digitais, abrangendo uma população de 22 milhões de usuários entre 15 e 24 anos de idade e que só estão conectados há pelo menos 5 anos [GLOBO NEWS, 2014].

Considerando que grande parte desse público encontra-se em fase escolar, compreende-se que aliar os recursos disponibilizados pelas redes sociais ao processo de ensino e aprendizagem pode ser uma contrapartida positiva para o uso das tecnologias em sala de aula, já que alunos e professores fazem uso delas em seu cotidiano, nas mais diversas situações.

Ao propor práticas de ensino que se desenvolvam além dos espaços escolares, busca-se o avanço que Schneider [2002] propõe através do diálogo com o saber que vai além do aqui e agora dos muros da escola e da sala de aula, mas que também se estabelece em espaços e tempos diversos, em outros moldes, numa concepção que Sibilia [2012] também compreende como mais compatível com os corpos e subjetividades do alunado atual.

A pesquisa em questão apresenta os dados preliminares de um estudo de caso desenvolvido para uma dissertação de mestrado (em andamento), que busca analisar como se dão as relações de graduandos de uma disciplina específica que se utiliza de uma rede social - o Facebook - como ambiente de aprendizagem informal complementar ao processo de estudo presencial, explorando as inúmeras possibilidades de convergência de mídias, realização de atividades e discussões acerca do processo de ensino e aprendizagem.

Para isso, defende-se que a prática docente esteja aliada a uma teoria que a sustente dentro das perspectivas de aprendizagem da atualidade, pois é na correlação teoria-prática que o professor encontra os caminhos que o levam ao efetivo exercício da docência.

Com base no estado da arte levantado acerca do objeto da pesquisa e em autores que discutem a prática e a formação docente na atualidade, é recorrente a importância da aprendizagem colaborativa para a prática que se faz mediante as redes sociais online, porém, compreende-se que esta teoria pode ser desenvolvida com ou sem recursos tecnológicos.

Nesse sentido, a proposta que mais se aproxima do ensino que explora os diversos recursos da web 2.0 no processo seria a de abordagem conectivista (SIEMENS, 2006), que tem como foco a mudança de paradigma no estilo de aprendizagem em sala de aula, indo além do espaço físico ao se apropriar das inúmeras ferramentas online e da facilidade de acesso para a construção de um ambiente de aprendizagem 3.0.

A problemática da pesquisa está situada na forma como o professor pode se apropriar da convergência de recursos midiáticos proporcionada pelas redes sociais online a fim de promover uma aprendizagem mais efetiva e quais as principais dificuldades enfrentadas em sua realização. Através dos dados coletados em um questionário com perguntas abertas e fechadas, buscou-se identificar as percepções do aluno diante da prática, a fim de encontrar subsídios que forneçam novas categorias de análise a serem exploradas posteriormente, em um grupo focal. 


\section{2. (Re) pensando a prática docente em tempos de conectivismo pedagógico}

Nas últimas décadas, as TIC vêm modificando os estilos de vida e, na perspectiva do estudante atual, a sala de aula tem se tornado um lugar sem atrativos, que a frequentam por uma convenção social, por determinado tempo, até que a abandonem por completo, considerações estas feitas por Sibilia [2012], baseadas em pesquisas feitas por uma instituição privada nacional. Segundo a autora, os altos índices de evasão escolar estão diretamente ligados ao desinteresse do aluno pela escola tradicional, cujos resultados mostram "que manter o jovem na escola não é somente uma questão econômica" e que é preciso "criar e atender a demanda por educação", garantindo "a atratividade da escola" [2012, p. 65 e 66].

Isso significa que a escola precisa mudar, sair de seu lugar comum, se quiser garantir seu espaço na sociedade atual. Para alguns, imaginar outros espaços além da escola (informais ou não) como possibilidades de transmissão do saber pode até ser difícil, mas Sibilia [2012] relembra que esse modelo de escola tal como se conhece (e sem o qual parece difícil se conceber a educação) também se constitui como uma tecnologia de época, estabelecida a partir do século XVIII em uma cultura bem definida, a fim de atender às demandas específicas do projeto moderno que a planejou: adestrar as crianças para sua atuação na vida adulta a partir de uma disciplina extremamente autoritária.

Por isso, Valente [1999] afirma que pensar nos contextos formativos é pensar a construção do futuro das instituições educativas, um futuro mais funcional, baseado nas diferenças entre as variedades das realidades formativas atuais e as instituições educativas tradicionais, entre as formas contemporâneas de comunicação e as utilizadas no século passado, entre as redes de organização social atuais e suas precedentes. Concorda-se com o autor [idem, p. 29] quando ele afirma que a mudança pedagógica necessária "é a passagem de uma educação totalmente baseada na transmissão da informação, na instrução, para a criação de ambientes de aprendizagem nos quais o aluno realiza atividades e constrói o seu conhecimento".

Isso porque novas formas sociais necessitam de novos modelos teóricos educacionais, uma vez que os anteriores primavam pela memorização e armazenamento de conhecimentos consolidados em livros e enciclopédias, enquanto os processos cognitivos atuais baseiam-se nas trocas de informações e na aprendizagem dos indivíduos a partir de conexões: um modelo mais complexo, formado por diversas fontes de conhecimento e cujo núcleo de interesses muda constantemente [RENÓ, VERSUTI e RENÓ, 2012].

Porém, a adaptação da escola às formas de lidar com o conhecimento e a informação na atualidade requer mudanças pedagógicas relacionadas à condução dessa geração [MOTA, 2009]. Isso porque para se desenvolver a autonomia e o controle do processo de aprendizagem do aluno faz-se necessário o emprego de pedagogias participativas, baseadas na colaboração, no diálogo e na cooperação. Quando não há essa abertura didática, ocorrem desgastes na tentativa de manter a ordem e postura tradicionais em uma escola cujas tecnologias são incompatíveis com os estilos de aprendizagem e comunicação de seus estudantes. 
Sibilia [2012] faz uma analogia à educação, comparando-a a uma máquina, cujas engrenagens devem estar bem ajustadas e lubrificadas, caso contrário haverá perda da eficácia, proposição também defendida por Pireddu [2008], que questiona a eficácia de um sistema que não mais responde aos anseios da sociedade:

Se as instituições predispostas à formação devem, de algum modo, acompanhar as pessoas durante suas vidas, ajudando-as a aprender e a atingir os próprios objetivos, faz sentido repropor um sistema que não tenha mais nada a ver com a sociedade viva e ativa que está à nossa volta? As mudanças sociais, culturais, econômicas das últimas décadas não podem ser ignoradas de modo algum pelos sistemas formativos [PIREDDU, 2008, p. 183].

Assim, dialoga-se com Pireddu quando este afirma que o ideal seria questionar se o que os alunos aprendem hoje é atual e útil, pois, assim como propõe Schneider [2002], compreende-se que o ensino não pode estar ancorado no conteúdo das disciplinas, baseado apenas em informações passadas pelo professor, sem considerar as experiências do aluno, suas práticas, suas vivências do cotidiano, suas intuições e percepções. O autor propõe um ambiente onde a tecnologia é utilizada para facilitar a comunicação entre todos-todos, facilitando o acesso à informação e funcionando como suporte à aprendizagem. Apoiado nela, afirma Schneider [2002], o aluno constrói seu próprio conhecimento, com a tecnologia funcionando como elemento de suporte, ao permitir "estabelecer uma comunicação ininterrupta síncrona e/ou assíncrona entre estudantes, professores e demais envolvidos no processo de ensino-aprendizagem", possibilitando maior facilidade de acesso à informação [idem, p. 131-132].

Para isso, é preciso que o professor assuma uma atitude mais ativa diante das mudanças sociais e comunicacionais de seus alunos, incentivando atividades que promovam o desenvolvimento de novas competências, como criatividade, colaboração e autonomia cognitiva [SCHNEIDER, 2013]. Aos gestores de ensino, é preciso investir na formação docente voltada para o trabalho com as tecnologias de forma a oferecer aos alunos a pesquisa e a colaboração como estratégias para a construção de conhecimento, sempre partindo do diálogo com os professores [SCHNEIDER, 2002]. Dessa forma, a escola estará se conectando com o ciberespaço, extrapolando as fronteiras do ato de aprender, sem necessidade de tempo nem de espaços pré-estabelecidos.

Para Fava [2012], uma educação nesses moldes tem por foco o desenvolvimento de uma pedagogia participativa entre docentes e discentes a partir de uma nova metodologia que prepare o estudante para a dinâmica de mundo no qual está inserido, dinâmica que não possui uma forma definida, mas muda constantemente. Trata-se de preparar o aluno para um futuro desconhecido, "no qual eles sobreviverão não pelo que sabem, mas pelas suas habilidades e competências para a busca e aplicação da informação e para a adaptabilidade a um ambiente em constante mutação" [idem, p. 14].

Segundo Siemens [2004], normalmente associa-se a aquisição do conhecimento à aprendizagem formal, porém, tal processo pode ocorrer sob as mais diversas formas, seja na aprendizagem informal, seja através da experimentação, da reflexão e do diálogo. A aprendizagem não ocorre à margem das nossas vivências, ela é contínua e, para o autor, as escolas precisam abandonar a visão de aprendizagem como algo que 
tem um começo, um meio e um fim, mas que vai além, podendo estar presente em todas as áreas da vida e ocorrer em qualquer momento, em qualquer lugar, formalmente ou não; ainda, ela pode ocorrer até mesmo fora do indivíduo, a partir da conexão entre conjuntos de informação.

Nesse caso, são as conexões que nos permitem aprender a aprender e se tornam, assim, elementos de grande importância para o processo de aprendizagem contínua. Por isso, defende que a prática pedagógica seja conectivista, que estabeleça a interseção entre entre aquilo que o aluno quer aprender ao que ele necessita, em interação com o todo, com seu contexto pessoal e com o mundo.

Alertando sobre a importância do contexto escolar e das práticas docentes, Renó, Versuti e Renó [2012], discutem a expansão dos conteúdos digitais e a necessidade de mudança no perfil docente para que as estratégias sejam, de fato, inseridas, questionando, ainda, se as salas de aula estão preparadas, em termos de infraestrutura e conexão e, principalmente, se o docente é conhecedor e também usuário de ambientes digitais e redes sociais, a fim de que possa fazer deles bom uso pedagogicamente.

\section{Metodologia e Resultados}

A pesquisa, de abordagem qualitativa, guiou-se pelo método do estudo de caso e foi desenvolvida com uma turma de graduação, na disciplina Português Instrumental, ofertada pelo Departamento de Letras Vernáculas - DLEV- da Universidade Federal de Sergipe, ministrada no período de 2013/1, no Campus São Cristóvão/SE. Os sujeitos da pesquisa foram treze dos dezessete alunos ativos na disciplina, cujas aulas foram ministradas no turno matutino, às terças e quintas-feiras, com carga horária de 60 horas.

A proposta de adoção de um ambiente online que servisse de comunicação entre todos e onde fosse possível postar arquivos e explorar recursos diversos de apoio à aprendizagem em sala de aula foi apresentada na primeira aula, baseada na proposta do conectivismo pedagógico, o qual, conforme Siemens (2006), está na associação da aquisição do conhecimento "formal" às diversas possibilidades de aprendizagem "informais", seja através da experimentação, da reflexão e do diálogo. Isso porque a aprendizagem não ocorre à margem das nossas vivências, ela é contínua.

Algumas redes sociais foram sugeridas, como o Facebook, o Orkut, um Blog ou ainda o sistema acadêmico da própria universidade (SIGAA). Pensando na necessidade desse ambiente oferecer recursos como chat, postagem de arquivos, organização de fóruns e enquetes, disponibilização de links e arquivos de mídias, como vídeo e músicas, escolheu-se o Facebook, uma proposta aceita pela maioria. Definiu-se então a criação de um grupo fechado sob administração da docente, por questões de privacidade.

A utilização do Facebook nos processos educativos está de acordo com o que apontam Marcon, Machado e Carvalho [2012, p. 2], que defendem o uso de suas ferramentas dentro de uma lógica comunicacional, destacando suas características inerentes: "a participação, a interatividade, a comunicação, a autonomia, a cooperação, o compartilhamento, a multidirecionalidade".

O Facebook foi utilizado na disciplina como um ambiente de ensino online, onde foram disponibilizados pela professora os materiais utilizados em sala (textos, 
slides, etc.), vídeos e links para discussão, foram propostos fóruns acerca de assuntos relacionados à disciplina, textos colaborativos, atividades e listas de exercícios seriam postados pelos alunos (com prazo para postagem), dentre outras atividades.

Durante o processo, foram analisadas as postagens dos alunos, a frequência no ambiente e o atendimento aos prazos. Para isso, foram feitos printscreens do ambiente. Além disso, a opção do bate-papo funcionou como um recurso para a interação professor-aluno, permitindo à pesquisadora aprofundar algumas questões e sondar as perspectivas do estudante.

Ao final do curso, a fim de coletar dados que levassem a compreender como os alunos avaliavam os recursos utilizados no Facebook que o aproximam de um AVA, aplicou-se um questionário com questões abertas e fechadas, o qual permitiu um levantamento bastante relevante da proposta de intervenção usando o site de rede social. Considera-se de grande relevância a aplicação deste instrumento, pois, diante dos dados obtidos, foi possível esquematizar as questões a serem levantadas futuramente, em um grupo focal composto pelos graduandos das licenciaturas, a fim de verificar a perspectiva dos futuros docentes. A fim de preservar a identidade dos participantes, seus nomes foram substituídos pelos nomes das letras do alfabeto grego.

Inicialmente, chama a atenção a boa aceitação da proposta por parte dos alunos, atestam as falas abaixo, a partir do questionamento acerca de suas perspectivas iniciais:

\footnotetext{
"Melhor para absorver o conteúdo, de maneira tranquila e interativa" [ALFA];

"Promover um debte coletivo, que acarreta na diversidade de opiniões" [OMICRON];

"A princípio interessante e uma maneira de explorarmos por mais tempo a disciplina, podendo estudar no trabalho, em casa..." [DELTA];

"Uma forma de interação boa entre professor e aluno e aluno e alunom até então pouco usado na UFS" [GAMMA];

"Foi uma proposta inovadora, pois nenhum professor na Universidade trabalhou esse método comigo" [BETA].
}

A perspectiva positiva está de acordo com o que Arantes, Freire e Simioni [2013] evidenciaram em suas pesquisas acerca do uso de redes sociais: cada vez mais os alunos reivindicam seu uso, pois as utilizam como espaço de interação, encontro, entretenimento e, até mesmo, para mobilização sócio-política. Em sua pesquisa, os autores evidenciaram a hegemonia do Facebook diante de outras redes sociais: dos participantes de sua pesquisa (professores ou não), 93\% utilizam o Facebook e desses, $55 \%$ consideram útil sua utilização de maneira didática.

Destaca-se que, dentre os entrevistados, 38\% tiveram alguma experiência didática anterior a essa em que o professor utilizou alguma rede social, os demais, a exemplo do aluno Beta, nunca participaram de atividade semelhante, aspecto bastante significativo, visto que pesquisas envolvendo redes sociais têm sido discutidas desde 2005, embora envolvendo o Facebook somente a partir de 2012 (seis anos após sua criação), conforme a levantamento do estado da arte da pesquisa em andamento [SOUZA, s. d.]. 
Um dos entrevistados apresentou uma perspectiva negativa, justamente aquele que não possuía uma conta ativa: "eu não tinha conta e me vi obrigada a fazer por ser um requisito obrigatório da disciplina" [PSI]. Durante as aulas presenciais, a aluna se mostrava arredia em usar o Facebook, mas sempre postou as atividades sugeridas no prazo estipulado. Ressalta-se o fato de que houve um entendimento entre todos os alunos de que se estabelecesse um ambiente online e, de forma democrática, a maioria escolheu o Facebook. Porém, é preciso levar em consideração que nem todo aluno estará receptível, para esta ou qualquer outra proposta.

Em relação ao aprendizado dos conteúdos, 54\% dos entrevistados afirmam que a proposta facilitou muito, $31 \%$ considera que facilitou um pouco, enquanto $15 \%$ acredita que prejudicou. Dentre aqueles que consideraram a proposta válida, alguns afirmam que:

\footnotetext{
"Consegui mais tempo para a disciplia" [DELTA];

"Tivemos acesso a vídeos, imagens, etc., que ajudaram a fixar o assunto" [PHI];

"Em relação ao tempo de aula, com o Facebook passou a ser maior" [BETA];
}

Para aqueles que consideraram a proposta prejudicial, os motivos foram "não tinha tempo de ir em lan house" [SIGMA] e "os alunos tinham que interagir em troca de pontuação" [PSI]. O aluno Sigma justificou sua situação, pois trabalha durante o dia e estuda à noite além disso etambém não possui acesso à internet em casa, situação que precisa ser levada em conta quando forem estabelecidas as regras para postagens e o peso das atividades, para evitar que o aluno fique prejudicado. No caso em questão, o aluno não sofreu quaisquer prejuizos, uma vez que podia realizar outras atividades em sala de aula. Em relação à aluna Psi, percebe-se que ela não compreendeu que a questão estava relacionada ao aprendizado dos conteúdos e não à interação entre os colegas.

Em relação à colaboração, $85 \%$ dos entrevistados consideram que houve colaboração entre eles, que pode ser melhor visualizado através da figura 1:

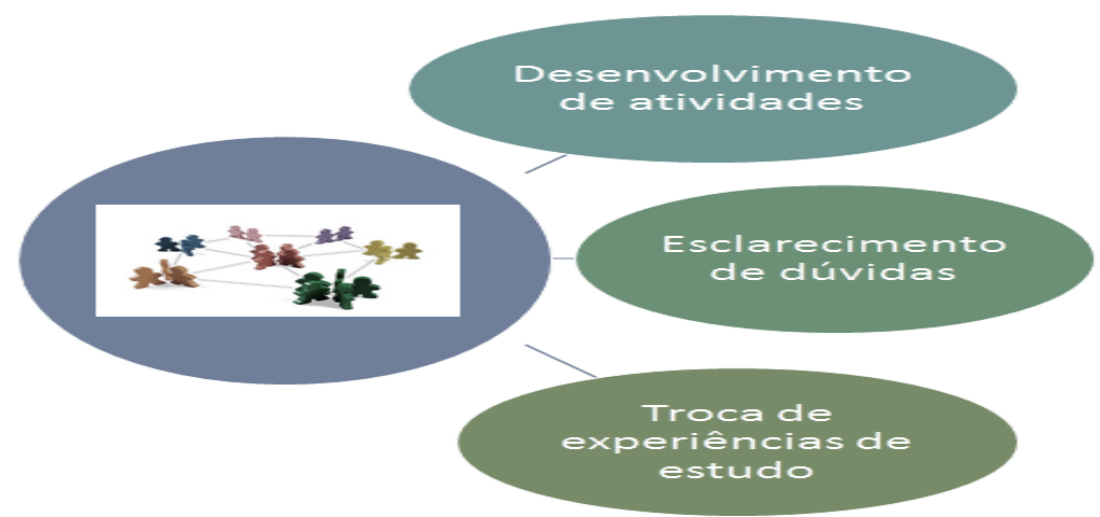

Figura 1: Como se deu a colaboração entre alunos

Destaca-se que como colaboração, compreende-se o conceito, já apresentado em outro trabalho [SOUZA e SCHNEIDER, 2013, p. 6], que diz respeito "à aprendizagem que ocorre e se desenvolve a partir da interação entre os indivíduos, numa proposta de 
construção do conhecimento movida pelas experiências partilhadas", promovendo novos conhecimentos a partir daqueles que os geraram.

Em relação à participação do aluno na disciplina, 70\% considera que o uso do Facebook como ambiente de estudo motivou bastante, 15\% afirma que motivou um pouco e $15 \%$ considera que a proposta não motivou sua participação. Os dados foram corroborados a partir do acompanhamento feito no grupo do Facebook, pois mais de $70 \%$ das atividades propostas eram postadas dentro dos prazos e, segundo a ferramenta disponível que comprova a visualização de membros do grupo diariamente, mais de $55 \%$ dos alunos visitavam a página do grupo diariamente. Observem-se as imagens abaixo, em dois dias distintos, destacando a quantidade de alunos que visualizaram o post no dia em questão:

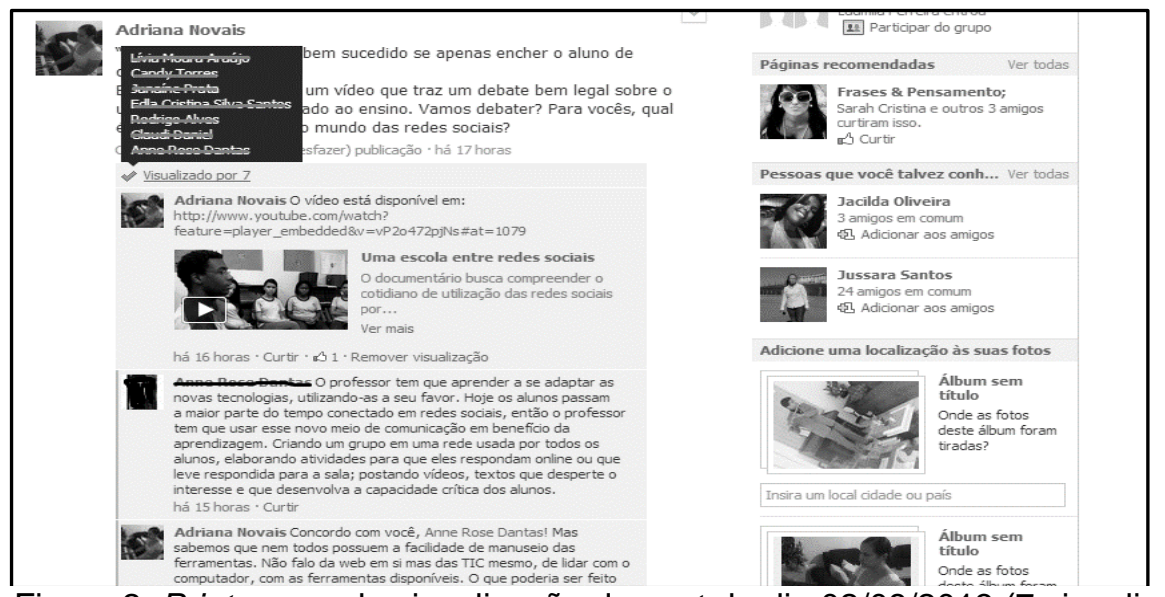

Figura 2: Printscreen de visualização de post do dia 02/08/2013 (7 visualizações)

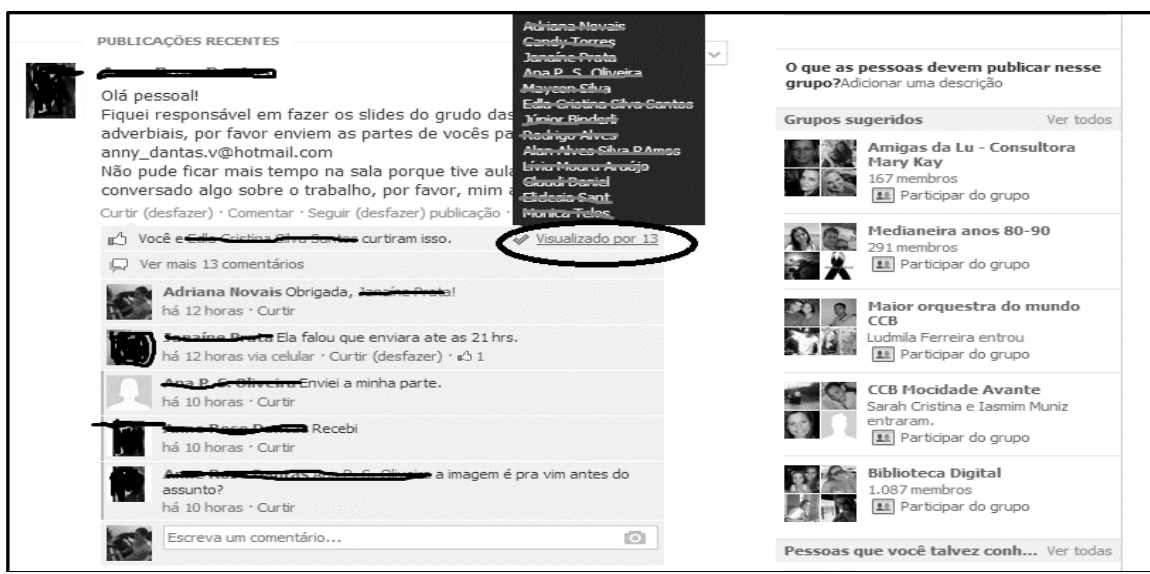

Figura 3 Prinstscreen de visualização de post do dia 04/08/2013 (13 visualizações)

Quanto aos recursos disponíveis e utilizados durante a disciplina, destacam-se a ferramenta de postagem e arquivamento de documentos, a possibilidade de maior contato e atualização através dos avisos e notícias entre todos, o uso do bate-papo, os fóruns e a disponibilização de links para complementação e aprofundamento do conteúdo. 
A proposta de utilização do Facebook além de simples repositório de materiais diversos dialoga com Barcelos e Batista [2012], ao proporem que se vá além, questionando o valor dessas redes, buscando "compreender como os nós interagem e estabelecem entre si colaboração da aprendizagem", a fim de proporcionar uma experiência que "ultrapassem tais situações, analisando a utilização da rede social como recurso didático e ferramenta de apoio ao processo de ensino e aprendizagem" [SOUZA e SCHNEIDER, 2013, p. 9].

\section{Considerações finais}

As discussões aqui levantadas fundamentam a utilização das redes sociais no contexto educativo por compreender a necessidade da escola em acompanhar a evolução que transformou as formas comunicativas e sociais entre as pessoas, envidando esforços para garantir a participação e interação do aluno em seu processo de construção do conhecimento.

Trata-se de um processo fundamental para que ocorra uma aprendizagem mais efetiva, renovadora, capaz de envolver a participação de todos, independente de idade, tempo e espaço. Para isso, é importante que o professor se torne, ele mesmo, usuário das ferramentas disponíveis nas redes sociais, explorando ao máximo suas potencialidades, participando de grupos, especialmente aqueles voltados para as práticas de ensino, afinal, a participação é o primeiro passo para essa apropriação, pois nunca se poderá utilizar com precisão uma ferramenta que não se conhece.

A proposta de que um dos mais acessados sites de rede sociais, o Facebook, seja incorporado como ambiente de interação e comunicação pedagógicos se dá por sua arquitetura atraente, com ferramentas que permitem desenvolver diversas atividades e instigam a participação, protagonismo, colaboração e horizontalização das relações entre professores e alunos. Isso não quer dizer que o papel docente seja dispensável, ao contrário, a partir das experiências efetivadas nas pesquisas, fica evidente a importância do papel do professor, pois ele será o guia e mediador do processo de construção do conhecimento, oferecendo o norte para que o desempenho do discente.

Assim, segundo uma perspectiva dos próprios alunos, dentre os quais existem licenciandos e, posteriormente, futuros docente, avalia-se o uso do Facebook numa proposta de utilização como ambiente informal de aprendizagem em concomitância com o ensino presencial como capaz de facilitar o acesso do aluno aos conteúdos, motivar a participação e potencializar a colaboração entre os participantes.

\section{Referências}

Arantes, F. L.; Freire, F. M. P.; Simioni, B. Estudo de viabilidade sobre o uso de Chatterbots em redes sociais para acessar ambientes de e-learning. In: "Anais do XIX Workshop de Informática na Escola". Campinas, SP, 2013.

Barcelos, G. T.; Batista, S. C. F. Rede social na internet como apoio à formação docente. "Anais do XVIII Congresso Brasileiro de Informática na Educação". Rio de Janeiro, nov. 2012. 
Ciribelli, J. P.; Paiva, V. H. P. Redes e mídias sociais na internet: realidades e perspectivas de um mundo conectado. Revista Mediação, Belo Horizonte, v. 13, jan/jun 2011. Fava, R. "Educação 3.0: como ensinar estudantes com culturas tão diferentes". 2a Ed. Cuiabá: Carlini e Caniato, 2012.

Globo News. Brasil é o quarto país com mais nativos digitais. "Jornal das 10". Publicado em 13.05.2014. Disponível em: http://globotv.globo.com/globonews/jornal-das-dez/v/brasil-e-o-quarto-pais-com-mais-nativos-digitais/3344231/. Acesso: 18.06.2014.

Kerckhove, D. Da democracia à ciberdemocracia. In: Felice, M. Di (org.) "Do público para as redes: a comunicação digital e as novas formas de participação social". 1 ed. São Caetano do Sul, SP: Difusão Editora (Coleção Era Digital; v. 1), 2008.

Marcon, K.; Machado, J. B.; Carvalho, M. J. S. Arquiteturas pedagógicas e redes sociais: uma experiência no Facebook. In: "Anais do XVIII Congresso Brasileiro de Informática na Educação”. Rio de Janeiro, RJ, nov. 2012.

Mota, J. C. "Da web 2.0 ao e-learning 2.0: aprender na rede". Dissertação de mestrado. Universidade Aberta. Lisboa, Portugal, 2009.

Pireddu, M. Do fornecimento à participação. O aprendizado entre modelos teóricos e tecnologias. In: Felice, M. Di (org.). "Do público para as redes: a comunicação digital e as novas formas de participação social". 1 ed. São Caetano do Sul, SP: Difusão Editora (Coleção Era Digital; v. 1), 2008.

Renó, D. P., Versuti, A., Renó, L. T. L. Transmediação e conectivismo: contemporaneidade para a educação. In: Linhares, R. N., Lucena, S. Versuti, A. (org.) "As redes sociais e seu impacto na cultura e na educação do século XXI". Fortaleza: Edições UFC, 2012.

Schneider, H. N. A educação na contemporaneidade: flexibilidade, comunicação e colaboração. In: "Int. J. Knowl. Eng. Management”, Florianópolis, v. 2, n. 2, p. 86104 , mar./maio, 2013.

"Um ambiente ergonômico de ensino-aprendizagem informatizado". Tese de Doutorado. Florianopolis-SC: UFSC, 2002.

Sibilia, P. "Redes ou paredes: a escola em tempos de dispersão". Trad. Vera Ribeiro. Rio de Janeiro: Contraponto, 2012.

Siemens, G. "Conectivismo: Uma Teoria de Aprendizagem para a Idade Digital”. Trad. Bruno Leite, 2004. Disponível em: http://pt.scribd.com/doc/66317606/Conectivismouma-Teoria-Para-a-Era-Digital. Acessado em: 04.02.2014.

Souza, A. A. N. "Prática docente conectivista: o Facebook como ambiente promotor da coaprendizagem". Dissertação de mestrado em andamento. Universidade Federal de Sergipe. São Cristóvão: SE, s.d.

Souza, A. A. N.; Schneider, H. N. Uso do Facebook como Recurso de Avaliação da Aprendizagem. In: "Anais do XIX Workshop de Informática na Escola". Campinas, SP, 2013.

Valente, J. A. Mudanças na sociedade, mudanças na Educação: o fazer e o compreender. Cap. 2. In: Valente, J. A. (org). "O computador na sociedade do conhecimento". Campinas, SP: Unicamp/ NIED, 1999. 